Northwestern University School of Law Northwestern University School of Law Scholarly Commons

Faculty Working Papers

2008

\title{
A New (and Better) Interpretation of Holmes's Prediction Theory of Law
}

Anthony D'Amato

Northwestern University School of Law, a-damato@law.northwestern.edu

\section{Repository Citation}

D'Amato, Anthony, "A New (and Better) Interpretation of Holmes's Prediction Theory of Law" (2008). Faculty Working Papers. Paper 163.

http://scholarlycommons.law.northwestern.edu/facultyworkingpapers/163 


\title{
A NEW (AND BETTER) INTERPRETATION OF HOLMES'S PREDICTION THEORY OF LAW
}

\author{
Anthony D'Amato * \\ Speaking to a distinguished audience of lawyers and judges in downtown Boston \\ in 1897, attorney Oliver Wendell Holmes, Jr., presented a definition of law that they had \\ not heard before:
}

The prophecies of what the courts will do in fact, and nothing more pretentious, are what I mean by the law. ${ }^{1}$

The audience had entered the theatre probably thinking law to be a "brooding omnipresence in the sky," ${ }^{2}$ as Holmes was to characterize it twenty years later. After hearing Holmes speak, the scholars and practitioners in the audience undoubtedly understood him to be comparing a lawyer with other public predictors of events such as weather forecasters. This particular comparison has become the standard interpretation of Holmes's prediction theory. Thus a lawyer predicts judicial decisions (which constitute the law), and the meteorologist predicts tomorrow's weather. It is as if standard interpreters have the following diagram in mind:

$$
\begin{aligned}
& \text { Forecast } \rightarrow \text { weather } \\
& \text { Prophecy } \rightarrow \text { law }
\end{aligned}
$$

\footnotetext{
* Leighton Professor of Law, Northwestern University.

${ }^{1}$ Oliver Wendell Holmes, Jr., The Path of the Law, 10 Harvard Law Review 460-61 (1897).

${ }^{2}$ Oliver Wendell Holmes, in Southern Pacific v. Jensen, 244 US 205, 222 (1917).
} 
But if we peruse exactly what Holmes said, we get the following quite different diagram:

$$
\begin{aligned}
& \text { Forecast } \rightarrow \text { weather } \\
& \text { Prophecy }=\text { law }
\end{aligned}
$$

"What I mean by the law," Holmes said, are "the prophecies of what the courts will do in fact." The analogy to weather forecasting is inapposite. Nevertheless in the minds of most lawyers and scholars over the years, the analogy has overridden Holmes's meticulous grammar. Surely, the standard interpreters must reason that if the prophecy is the law, then the forecast is the weather, which is absurd. This would be a convincing argument except for the fact that the weather analogy does not capture what Holmes said. Indeed, Holmes's use of the word "prophecies" instead of the normal "predictions" may have been intended to call attention to prophecies as a substantive concept as opposed to, say, a forecasts which everyone regards as a mere prediction.

\section{WHAT THE STANDARD INTERPRETATION ACCOMPLISHED}

Holmes was taking two giant steps in his speech in downtown Boston. The first was to call attention to the central role of the lawyer as the predictor of what judges will do - what is herein called the standard interpretation. The second step was the assertion that the prediction itself constituted the law—which will herein be called the quantum interpretation, for reasons to be given later. Holmes's first step was so radical that $\mathrm{h}$ is 
audience grudgingly accepted it; his second was apparently too radical to be understood at all..

The first step, in and of itself, was enough to shift the legal paradigm. For centuries up to 1897, lawyers, judges, scholars, and the general public viewed law as something that exists in the present - the time when people make decisions that are influenced by the content of preexisting law. Holmes was now apparently informing everyone that law does not exist in the present. It only comes into existence in the future when courts issue their rulings - after people have made their decisions. In the present we are remitted to guessing — making prophecies — about what the law might turn out to be. All this of course is the standard interpretation, the first radical step that Holmes took.

It took two decades for the standard interpretation of Holmes to conquer the lawschool world. In the 1920s and 1930s, when the older professors had been replaced by younger ones, ${ }^{3}$ the enthusiasm of the new generation for the possibilities opened up by the prediction theory led to the movement that became known as called legal realism. Its core idea was that if making prophecies of judicial decisions is the game lawyers play, then it is the professional duty of law schools to teach future lawyers how to play the game better so as to improve their odds of winning. Since there is nothing to prevent judges being motivated by non-legal or extra-legal ideas, the curriculum ought to be expanded to include subjects other than the traditional ones. Why teach restitution, damages, bills and notes, and agency, when they can be replaced by courses in policymaking, social welfare and interviewing techniques? If the goal is to turn out effective

\footnotetext{
${ }^{3}$ This is the typical pattern of paradigmatic revolutions as put forth by Thomas S. Kuhn, The Structure of Scientific Revolutions 151 (1962).
} 
attorneys, then the curriculum should be expanded to include subjects that could motivate judges. 4

But far more important than the impact of legal realism upon attorneys and law professors was its psychological impact upon judges. Every judge in the United States is a former law student. A future judge, sitting in a classroom in the 1920s or 1930s, might have experienced a rush of empowerment upon realizing that all his classmates are studying the law in the hopes that someday they might influence him. Better yet, once he becomes a judge, he will not have to pay much attention to what the lawyers say about the law (any more than he did in the classroom). For the "law" will be whatever he proclaims it to be.

Because professors knew that some of their students would become judges, their decision to offer peripheral subjects served to legitimize those offerings. Thus a course in law and social policy, which before legal realism would have been deemed irrelevant to studying law, became relevant because future judges would look back on their legal training and assume that social policy was part of the law. Thus legal realism in the curriculum became a self-fulfilling prophecy_-surely not the kind of prophecy Holmes had in mind.

The prediction theory of law - the standard version, that is - gradually but steadily swept the practicing bar. At first blush this seems counterintuitive: why would lawyers embrace a theory that presupposed their partial ignorance of existing law? The answer is that the prediction theory mollifies clients who are later disappointed. For if the

\footnotetext{
${ }^{4}$ Although this essay is not addressed to legal realism per se, one major objection to legal realism's use of the prediction theory should be mentioned. Suppose a sure way for a lawyer to increase his odds of winning a case would be to bribe the judge, does it follow that law schools should offer courses in the techniques of bribery and corruption? Legal realists have never satisfactorily drawn a line between bribery and other forms of extra-legal persuasion.
} 
attorney advises his client that there is a $75 \%$ (or any other numerical percent) chance of winning, then if the case is subsequently lost the attorney can explain that "we had three out of four chances of prevailing in court, but we were unlucky and the long-shot won." In Karl Popper's view, any prediction of a one-time event is not falsifiable. ${ }^{5}$ Hence the attorney's advice that the plaintiff has a $75 \%$ chance of winning it is not a scientific statement. Only theories that can be falsified are genuine theories. Suppose either of the following two propositions are asserted: "God exists" and "God does not exist." Since there is no evidence that would support or contradict either assertion, both are nonfalsifiable and unscientific.

If we spell out the premises in Holmes's aphorism, it reduces to the following logical sorites:

(1) prophecies exist in the present;

(2) prophecies are determinable (i.e., a numerical probability can be attached to them);

(3) the term "law" means either the precepts that affect or channel the choices people make, or the assemblage of precepts that can be found in law libraries and are modified or deleted by the application of other constitutional or juridical precepts.

(4) the law that affects human behavior is nothing but the prophecies of what courts will do in fact.

(5) the law that affects the choices people make in their everyday lives consists not of rules but of probabilities of rules.

\footnotetext{
${ }^{5}$ Popper argued that numerical probability statements are "impervious to strict falsification" (Popper's italics). Karl Popper, The Logic of Scientific Discovery (London: Routledge, 1959), p. 133..
} 
The foregoing propositions set forth the second interpretation of Holmes's prediction theory of law. Let us refer to the second interpretation as the quantum interpretation.

\section{THE QUANTUM INTERPRETATION}

Holmes meant exactly what he said in his speech of 1897 in Boston. Since he undoubtedly knew that his audience might misinterpret him, especially if he had tried out the idea on other groups before giving his talk, he introduced his now-famous "bad man" example to underline his point that it is the prediction itself that constitutes the law.

A [bad] man who cares nothing for an ethical rule which is believed and practiced by his neighbors is likely nevertheless to care a good deal to avoid being made to pay money, and will want to keep out of jail if he can. $^{6}$

Take the fundamental question, What constitutes the law? You will find some text writers telling you that it is something different from what is decided by the courts of Massachusetts or England, that it is a system of reason, that it is a deduction from principles of ethics or admitted axioms or what not, which may or may not coincide with the decisions. But if we take the view of our friend the bad man we shall find that he does not care two straws for the axioms or deductions, but that he does want to know what the Massachusetts or English courts are likely to do in fact. I am much of this mind. The prophecies of what the courts will do in fact, and nothing more pretentious, are what I mean by the law. ${ }^{7}$

Holmes's bad-man theory has been criticized from a moral perspective. ${ }^{8}$ Holmes may have invited such criticism by over-explaining the bad man's view of the law. Even so,

\footnotetext{
${ }^{6} 10$ Harv. L. Rev. at 459.

${ }^{7}$ Id. at $460-61$.

${ }^{8}$ See, e.g., Lon L. Fuller, The Law in Quest of Itself 58-63, 92-95 (1940).
} 
the bad-man theory forcefully explains that what courts will eventually decide in the case at hand case is not something that is knowable in the present and hence cannot affect the bad man's decision to go ahead with his plan. The only relevance the court's decision in the future would have to his decisional processes in the present is the present handicapping —or discounting —of what the court will likely decide. In short, it is the present probability of what the court will do that is of great interest to the bad man rather than the future fact of what the court will decide because by then it will be too late to influence the bad man's decision in the present.

Perhaps Holmes could have put the argument more simply, leaving out the bad man, in something like the following sorites:

(6) The purpose of the law is to influence people's decisions - to channel the decisions in certain directions and away from other directions.

(7) People make their decisions in the present, even though they intend to act in the future. Sometimes the duration between decision and action can be measured in milliseconds.

(8) If the law is to influence people's decisions, the law must operate in the present- "when the tire hits the road" in the colloquialism. .

(9) The law operates in the present.

(10) The content of the law in the present is a prediction of what courts will decide in the future.

(11) An allegedly applicable rule of law in the present is the probability that the rule will be affirmed by a court in the future. 
To this Holmes may have added that all decisions, not just those with legal consequences, are based on probabilities. For example, a jaywalker decides to cross the street. $\mathrm{He}$ figures that his chances of reaching the other side are $99.99 \%$ He has allowed $0.01 \%$ for the possibility that he will stumble halfway through and be run over by a passing car. On top of that calculation he must also consider the probability of being arrested for jaywalking — an arrest that would defeat his purpose of crossing the street in between the traffic signals. He looks around and does not see a police officer. Nevertheless he has to allocate some degree of probability that a police officer may be standing behind a truck parked on the other side of the street. Thus his probability of successfully jaywalking reduces from $99.99 \%$ to, say, $97 \%$. This probability may or may not lead him to decide to jaywalk. There may be other factors that enter into his decision. Every one of those factors can be measured as a numerical probability. His decision whether or not to jaywalk, just like every other decision he makes or will ever make, is based on the summation of all the relevant probabilities of which he is aware at the time he makes his decision.

Is there any field other than law where the prediction counts more than the end result? The answer, which may come as a surprise to many readers, is that the entire world that we inhabit consists not of solid matter but of probabilities. It is not a chair that we see but rather the probability of a chair. We do not see the moon but we see the probability that there is a moon where we are looking. The subatomic particles that make up each atom in the chair are in a constant whirl of activity that sometimes takes them outside the chair and around the earth a few times before returning, or not returning, to 
the chair. Then why doesn't the chair fly apart? For one thing, because there are other atoms in the vicinity of the chair that spiral into the chair to take the place of those atoms that have radiated away from the chair. A second reason is the fractional degree of freedom that the chair possesses. This means that the chair is far more likely to stay in place than to fly off somewhere else. The trillions of subatomic particles in the chair do not leave the chair at the same time- this is another way of saying that the chair has a minuscule degree of freedom. Moreover, when these particles leave the chair for a journey around the Andromeda galaxy, other particles leave the chair in the opposite direction, creating a net movement of zero for the chair itself. Third, the subatomic particles in the chair are not tiny bits of matter as the name implies. Rather every particle in the universe is made up of a wave and a particle. This wave-particle duality has never been pictured or described because it is unlike anything we see in our macro-world. When we look at a chair, we see it as an assemblage of particles. However, the electrons in the light beams that go from the chair and bounce back to our retina have interacted with the surface atoms of the chair so as to temporarily reduce the surface wave-particles into particles. As Heisenberg pointed out, it is the effect of our observation of the chair that creates for us the image of the chair. Every observation of every thing interferes with the thing we are observing. Our inability to observe anything in the world in its primal state is due to the fact that we disturb that which we are observing. This is Heisenberg's "uncertainty principle."

Although wave-particle duality has proved impossible to imagine, Schrodinger created a series of equations showing that the particle is somehow smeared out along a wave. Picture an ordinary Bell curve. Let the curve represent the path of an electron. If a

\footnotetext{
${ }^{9}$ Werner Heisenberg, The Physical Principles of the Quantum Theory 3 (1949).
} 
measurement of the electron is actually made - on a photographic plate or in a Wilson cloud chamber - then the electron will show up as a particle. The height (or amplitude) of the wave represents the probability of finding an electron at the point in the wave. Thus the electron is more likely to show up at the peak of the Bell curve than in either of its tails (which theoretically stretch out across the universe).

However, Heisenberg tells us that when we make a measurement of the electron, the measurement interferes with the electron. The reason is that the measuring instrument has to consist of a probe on the same scale as the electron it is measuring - for example, a photon of light or another electron on the photographic plate. As we measure our target electron, the probe interacts with the target, displacing it. Hence we can never know exactly where the electron is at the moment we measure it. The best we can do is use the Schrödinger equation to predict where the electron might show up if we conduct a measurement. The analogy to Holmes's prediction theory is compelling. We cannot know exactly what the law is right now when we want to factor it into our decision whether to act or not to act, but we can assign a numerical prediction in the present to what a court will later decide and treat the prediction as the law.

In physics, the Holmesian position was taken by Max Born, one of the founders of quantum mechanics. Born thought it absurd to say that we can only guess where an electron might be at the present moment by relying upon a measurement that has not yet taken place. Instead, he urged physicists to assume that where the electron is located right now is the correct starting point for analysis. In fact, we have a picture of where the electron is right now—Schrödinger's wave function. Born renamed it a probability 
wave $^{10}$. The true picture of the electron in the present is that it is nothing but a wave of probability. ${ }^{11}$ A common figure of speech is that the electron is smeared out all along the probability wave. When the wave is disturbed by a measuring probe, the wave function collapses and we find the electron in the form of a particle. But its particle form only represents where the electron is by virtue of its being jarred as a result of the measurement. Right before a measurement was made the only form any electron has is that of a probability wave.

But how could the probability wave itself be the electron? This question, which is analogous to the question of how a prophecy can itself be the law, greatly troubled Einstein. In striking parallelism, at the very time when American legal realism reached its apogee Einstein and two younger colleagues published a paper on scientific realism. ${ }^{12}$ He argued, in opposition to Born, that quantum mechanics cannot be a complete picture of reality. ${ }^{13}$ Born had argued that the probability of matter constituted present reality, just as Holmes had argued that the probability of law constituted present reality.

\footnotetext{
${ }^{10}$ See Max Born, The Statistical Interpretation of Quantum Mechanics 262 (Nobel Lecture 1954), at http://nobelprize.org/nobel_prizes/physics/laureates/1954/born-lecture.pdf .

${ }^{11}$ Born noticed that the second power of Schrodinger's wave function $\left(\Psi^{2}\right)$ is just the description of the probability of an electron being situated in a given place.

${ }^{12}$ See A. Einstein, B. Podolsky, \& N. Rosen, Can quantum-mechanical description of physical reality be considered complete? 47 Physical Review Letters 777 (1935).

${ }^{13}$ Einstein proposed an experiment that could falsify the proposition that electrons and other subatomic particles were just probabilities. He took advantage of a well-known phenomenon about 'paired electrons' - that if two electrons A and B are paired together in an AB combination, they will act as a unit even after they are divided by an electron splitter and go their separate ways. Thus if A originally had a clockwise spin it would retain its clockwise spin after being separated from $\mathrm{B}$, while $\mathrm{B}$, which by virtue of its having been being paired with A originally had a counterclockwise spin, would retain its counterclockwise spin after it was separated from A. Inasmuch as Heisenberg had demonstrated the impossibility of knowing any of two conjugate variables of an elementary particle - in this case, of knowing both the location and the spin of a single electron-Einstein proposed two measurements to be taken after the electrons were separated by the splitter. The first would be the measurement of A's spin, the second would measure B's position. Measuring A's spin would then reveal B's spin by logical implication, since B's spin will be the opposite of A's. Then we combine our inferential knowledge of B's spin with the measurement we actually made of B's position. The bottom line is that we would presumably know B's spin s well as its location. This knowledge was what Heisenberg said was impossible to obtain. It would be blocked by the uncertainty principle.
} 
Yet Heisenberg's uncertainty principle by 1935 had been confirmed by hundreds of experiments and never disconfirmed. Einstein was not one to refute an experimental finding for the sake of a theory, even his own. ${ }^{14}$ Einstein was never able to reconcile his theory of 1935 with the increasing evidence that increasingly refined experiments would probably falsify his theory. In 1982 an experiment proved conclusively that Einstein's theory itself did not capture reality. ${ }^{15}$ We now know for certain that the material objects we see and touch in our macroworld appear solid only because they consist of vast and dense aggregations of subatomic probabilities.

The foregoing analogy of legal realism with physical realism in quantum theory should assist us in conceiving of law as having a probabilistic existence. At whatever degree of probability law has, it must exist in the present—at $t_{1}$. The judge's later measurement at $t_{2}$ should not affect what the law was at $t_{1}$. The idea of presentism may be referenced in support of this worldview. Philosophical presentists hold that the only reality in the universe is the one we experience at the present slice of time. Everything happens in the present and nothing happens in the past or in the future. ${ }^{16}$ The philosophers in effect have reinvented Holmes's picture of the bad man.

\footnotetext{
${ }^{14}$ Accordingly, when A's spin is measured, Einstein accepted the fact that B's spin must undergo a random change. This would be true even if at the moment of simultaneous measurement A is on Earth and B is four light-years away on Alpha Centuri. Heisenberg's uncertainty principle would thus be confirmed, but at the cost of assuming some kind of instantaneous communication between A and B - what has been called "spooky action at a distance." To avoid instantaneous communication (which moreover would require the message's speed to be faster than light in violation of Einstein's own special theory of relativity).

${ }^{15}$ See Alain Aspect, Jean Dalibard, \& Gerard Roger, "Experimental test of Bell's inequalities using timevarying analyzers," 49 Physical Review Letters 1804 (1982); Bernard d'Espagnat, In Search of Reality 3943 (1983).

${ }^{16}$ For a stimulating survey, see Thomas M. Crisp, "Presentism," in Michael J. Loux \& Dean W. Zimmerman (eds.) Oxford Handbook of Metaphysics 211 (2003).
} 


\section{SOME CONCLUDING CONSIDERATIONS}

The analogy with quantum mechanics should not be pushed too far. A vital difference is that in the quantum world a measurement of electron A will invariably randomize the behavior of its twin B even if, as recent experiments have shown, A's measurement is made after B's behavior is randomized. ${ }^{17}$ Although quantum mechanics is probabilistic, the aggregate probabilities can be measured accurately because the physical world is deterministic. By contrast, law proceeds on the assumption of free will. A judge's measurement of the law after the fact need not necessarily change or disturb the prior law. Yet there is an anomaly in the law whose analogy in quantum mechanics has been disproven.

Suppose after the facts occur at $\mathrm{t}_{1}$ a decision in a factually similar case is handed down in a neighboring jurisdiction. This decision makes a significant change in the law that existed at $t_{1}$. Then the judge in the first case at $t_{2}$ is faced with a dilemma. Does she

\footnotetext{
${ }^{17}$ Two of the most famous and baffling experiments are: (1) The Delayed Choice Experiment. Here an experimenter's decision to measure the orientation of the particle after the particle has passed a splitter somehow leads the particle to behave as if it had a precognition that an experimenter will soon measure its future path. (2) The Negative Result Experiment. Here a device is set up in which the experimenter can choose not to make a measurement of electron $\mathrm{A}$ and in fact does not make such a measurement. Electron $\mathrm{B}$ weirdly changes its behavior as if it had known in advance that the experimenter would not make the measurement. See John A. Wheeler \& Wojciech Zuerk, Quantum Theory and Measurement (Princeton: Princeton University Press, 1983); Paul C.W. Davies, The Ghost in the Atom (Cambridge: Cambridge University Press 1986), pp. 9-10; John Gribbin, Schrödinger Kittens and the Search for Reality (Boston: Little, Brown, 1995), pp. 138-144. These two results seem to deny to human observers any possibility of improving the predictive odds of measuring any more than one facet of an electron's existence. They seem to confirm Max Born's insistence that it is the prediction itself that is the only reality. They also confirm a logical inference of Born's theory that nothing subsequent to the prediction can alter the probability we have assigned to the prediction! It is almost as if nature is telling us that we cannot do in science what judges should not do in law, namely, change the law after the prediction is made.
} 
apply the law as it existed at $t_{1}$ or does she apply the law as it was developed in the neighboring jurisdiction in between $t_{1}$ and $t_{2}$ ? The first alternative would result in a clash of law between the judge's forum and the neighboring forum, making it difficult for future courts to choose the correct precedent. The second alternative would be unfair to the losing party, since he based his actions on the law at $t_{1}$ and could not have based it on the new law that was determined after he had acted. If there were an analogy to quantum mechanics in this example, it would be to the theory of hidden variables. ${ }^{18}$ But this oncepopular theory was falsified by the experiments of 1982 above mentioned. ${ }^{19}$ Thus the legal anomaly is unique. Jurisprudence has not solved it. As a practical matter, judges almost uniformly adopt the most recent precedent even if it occurred subsequent to the facts of the case at hand. This approach helps keep the law pure by being unfair to the losing party whose reliance upon existing law to order his affairs is generally deemed expendable by an unsympathetic judiciary. ${ }^{20}$

The quantum interpretation of Holmes's prediction theory of law may introduce a new agenda item in the teaching and practice of law. For the question is not whether the quantum interpretation is a better interpretation of Holmes than the standard interpretation, but whether it is a better interpretation of everyday law. If it is, then it cannot be brushed aside as only a debate about a nineteenth-century theory.

It may be warranted to say that legal realism was a disastrous setback for American law. It seemed to justify as an uncontestable fact of empiricism that judges

\footnotetext{
${ }^{18}$ See David Bohm \& B.J. Hiley, The Undivided Universe: An ontological interpretation of quantum theory 140-52 (1993).

${ }^{19}$ See supra n. 11.

${ }^{20}$ Sometimes, however, the decision in the neighboring jurisdiction could have been predicted by a clever attorney, in which case unfairness to the losing party is mitigated. However, the example in the text proceeds upon the assumption that the decision in the neighboring jurisdiction effected a significant change in the law and therefore was not predictable.
} 
may make all kinds of decisions based upon a wide range of factors: emotions, prejudices (unless they amount to a conflict of interest), party affiliation, rewarding campaign contributors, facile study of the law, liking or disliking the attorneys arguing a case, mere whim, and other bells and whistles. Law-school curriculums are then skewed to prepare students to argue successfully before judges who may only care minimally about what the law says. ${ }^{21}$

This essay has shown that legal realism was founded on a mistake, one that can be corrected by revisiting the standard interpretation of Holmes's prediction theory. All the implications of that mistake can and should be revised. The quantum interpretation has the virtue of focusing legal study and client counseling upon the attorney's prediction of the law. It takes the spotlight away from judges and their preferences and idiosyncracies. Holmes's radical new theory may have the unanticipated consequence of reintroducing into the law-school classroom an emphasis upon plain law without bells or whistles.

\footnotetext{
${ }^{21}$ The hit TV series "Boston Legal" depicts how successful lawyers manipulate judges, opposing counsel, and the police, and sometimes even lie, in order to win for their clients.
} 